Chapter 13

\title{
NETWORKED TECHNOLOGIES - THE ROLE OF NETWORKS IN THE DIFFUSION AND ADOPTION OF SOFTWARE PROCESS IMPROVEMENT (SPI) APPROACHES
}

PANEL 2

Karlheinz Kautz ${ }^{1}$, Linda Levine ${ }^{2}$, Bill Hefley ${ }^{3}$, Jørn Johansen ${ }^{4}$, Carsten Højmose Kristensen ${ }^{5}$, and Peter Axel Nielsen ${ }^{6}$

1 Copenhagen Business School,Denmark

2 Software Engineering Institute, Carnegie Mellon University, United States

3 IT Services Qualification Center, School of Computer Science, Carnegie Mellon University,

United States

4 DELTA, Denmark

5 Systematic Software Engineering A/S, Denmark

6Department of Computer Science, Aalborg University, Denmark

Abstract: Software process improvement (SPI) is a field of research and practice focused on improving the practice of software engineering by frequently introducing new methods and technical tools attuned to the managerial and processoriented aspects of software development. Social networks play a key role in the adoption and diffusion of software process improvement as a networked technology. This panel addressed actual examples of SPI networks and identified key characteristics of and roles in these emergent networks.

Key words: software process improvement, SPI, social networks, networks, adoption and diffusion 


\section{SOFTWARE PROCESS IMPROVEMENT}

\subsection{Background}

Software process improvement (SPI) is a field of research and practice, arising out of the need to solve software development problems such as unfinished projects, cost overruns, and erroneous systems or systems lacking functionality. Frequently, new methods and technical tools are introduced focused on managerial and process-oriented aspects of software development. SPI emerged as a result of US Department of Defence initiatives to develop a methodology to evaluate the capability of their software contractors (Humphrey and Sweet, 1987). The first widely recognized approach for this purpose was developed at the Software Engineering Institute (SEI) at the Carnegie Mellon University. The approach is based on the assumption that the quality of the development process has an influence on the quality of the product and became widely known through Watts Humphrey's book on 'Managing the Software Process' (Humphrey, $1989)$ which presented the Capability Maturity Model $\left(\mathrm{CMM}^{\circledR}\right)$ (Paulk, 1995) for software organizations to a broader audience. The basic intent was to apply the principles of total quality management (Dale et al., 1994) to software development by analyzing software practices and planning and implementing improvements in a step-wise manner as described in the model.

\subsection{Adoption and Diffusion of Software Process Improvement}

Beyond the concepts of adoption and diffusion, the theme of this conference emphasizes two terms - networked technologies-which play a central role in the context of this panel. Within the 8.6 working group, the concept of information technology is understood very broadly, spanning from Internet-based innovations to the use of system design methodologies and software process improvement approaches (Kautz, 2000).

The meaning of network requires clarification and goes far beyond a technical definition to deal with information technology and social networks, as discussed by Robertson et al. (1996) in the context of the adoption and diffusion of computer aided production management systems. If we understand software process improvement as an information technology and interpret the concept of network in this sense, then software process improvement clearly represents a networked technology. 
Shortly after the appearance of SPI in North America, the approach found wide acceptance around the world (SEI, 2003a) and in the Nordic countries of Europe in engineering-oriented communities and the telecommunications industry (see Mobrin \& Wästerlid, 1997). The roots in telecommunications run deep and relate, in part, to the development of related proprietary methods. Research and technology transfer agencies such as Delta in Denmark, Tieke in Finland, NR and Sintef in Norway, and IVF in Sweden promote these approaches (Kautz, 2001).

Both academic and practitioner conferences-The International Conference on the Software Process, The (European) Conference on Software Process Improvement, The (European) Software Engineering Process Group Conference-to name just a few, have developed and journals like SOFTWARE PROCESS-Improvement and Practice. And special issues of other mainstream journals are regularly devoted to this topic, e.g., IEEE Software (Curtis, 2000)

In 1994, the Commission of the European Communities launched the European Software Process Improvement Training Initiative (ESPITI) in 17 Western European countries (Kautz \& Larsen, 2000) to create awareness and support the uptake of SPI methodologies. As in many other countries, a government funded research project in co-operation with industry (Johansen \& Mathiassen, 1998) sustained the spread of the approaches in Denmark (Kautz \& Nielsen, 2000).

\section{PANELISTS}

This panel addressed the question of SPI as a networked technology by bringing academics and practitioners together who are actively involved in the spread of SPI approaches. Each panellist represented a different role/s and organization. The panellists' backgrounds included:

- founding members of the IFIP WG 8.6.

- participant in a technology transfer organization

- process consultant

- expert adviser for the EU and US governments

- action researcher

- manager of SPI consulting organization

- author of Capability Maturity Models

- participant in a professional association and SPI network

- assessor, with experience performing organizational diagnostics and process assessments

- participant in national/international research and diffusion projects 
- client for the services of several technology transfer and consulting organizations, and

- researchers in software process improvement, knowledge management, workforce management, and organizational improvement.

\section{SPI AS A NETWORKED TECHNOLOGY}

In the context of software process improvement, two key questions arise:

1. Whether and, if yes, which role(s) do the different organizations, agencies, and individual stakeholders play in the diffusion and adoption of these SPI approaches?

2. How do inter-organizational and interpersonal networks operate in such an environment?

\subsection{The Role of Stakeholders and Networks in SPI Adoption}

Panellists addressed the topic of networks in software process improvement, in the context of diffusion of SPI to individuals and organizations, and in the context of adoption of these practices within a software-producing organization. In these networks, a number of roles are filled by different organizations, agencies, and individual stakeholders. These roles include Researcher, Practitioner, Star, Gatekeeper, and Liaison.

In Figure 1, a basic Scandinavian network is shown. Key nodes include:

- researcher nodes, such as the node labelled "SEI";

- star nodes, representing professional groups, such as DELTA's SPI group, which is an example of a regional SPIN (software process improvement network) (Fowler, 1993; SEI, 2003b);

- gatekeeper nodes, such as that played by a key researcher at the University; and

- adopter organizations and their practitioners and liaisons, who serve to link these individual organizations to the larger network.

Nodes not represented in this figure, but which serve as transient organizational entities or groups in SPI adoption and diffusions, include conferences, such as the Nordic SPI conferences or the annual European SEPG conference. 


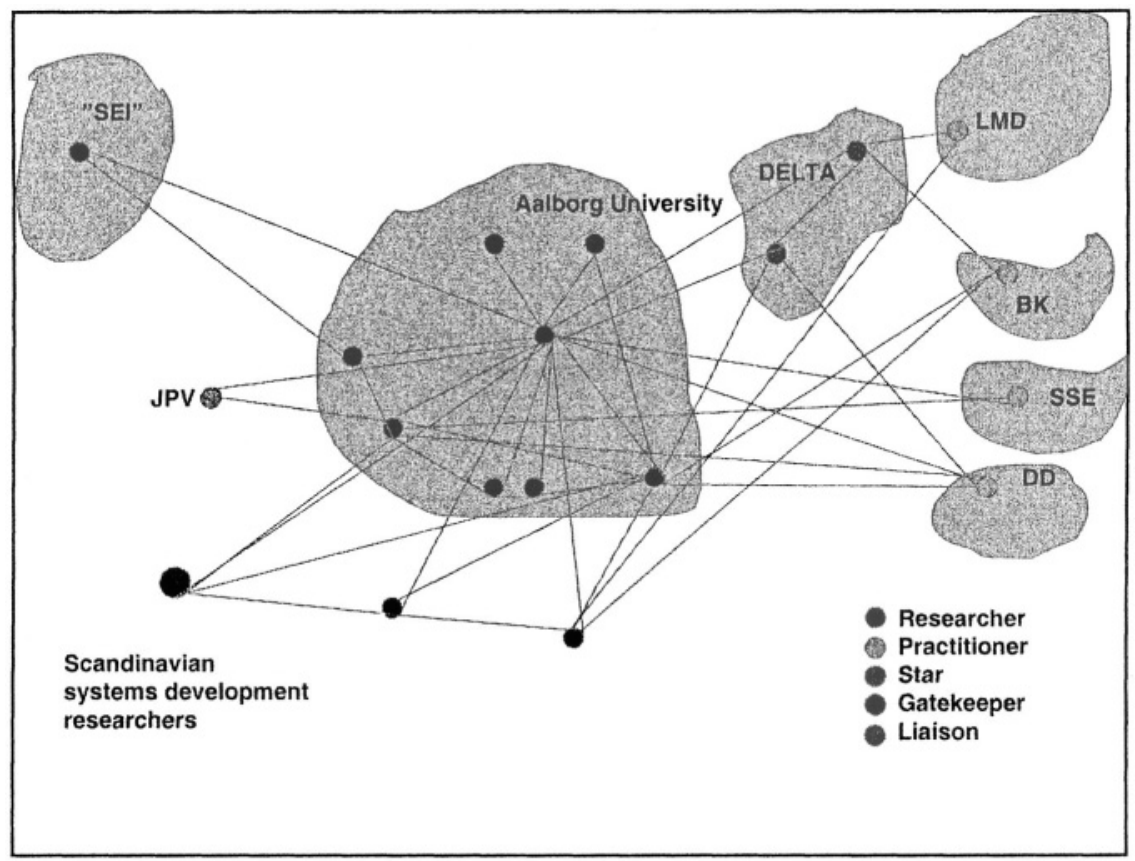

Figure 1. Basic Scandinavian Network [Source: Nielsen]

Figure 2 shows this basic network, overlaid with a map showing the extent of the overall Scandinavian SPI network. Changes over time in this network occur as a result of individuals moving on to new positions, such as has recently happened with the star node; organizational decisions about adoption or non-adoptions; and the use or non-use of various partly proprietary methods. A new network has evolved, focusing on knowledge management in software process improvement, but it has a different topology than other networks shown here because the star is no longer present in the network and fewer companies are involved. Thus, networks are established, are active for a while, and are partly dismantled, only to reemerge at a later stage in a new form. These networks are emergent organizations. In these networks, stars, gate keepers, and liaisons are relevant roles to perform. 


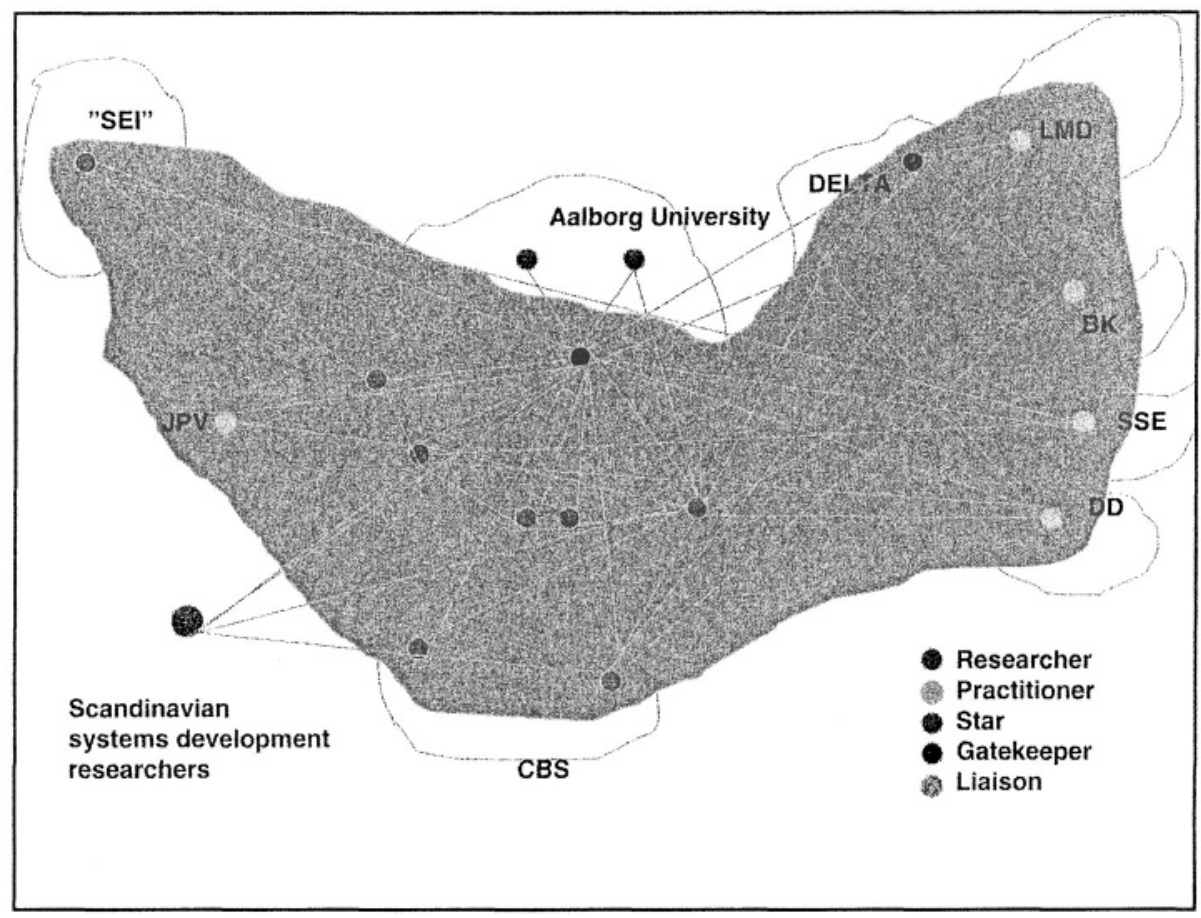

Figure 2. Scandinavian SPI Network [Source: Nielsen]

A number of forces affect these emergent networks, including:

- Individuals' interests

- Competition between research groups

- Outside influences from the research communities

- Financial conditions

- Confidentiality and intellectual property rights

A second set of networks were discussed that were internal to an adopting organization. Key roles in these networks include the practitioners or liaisons who link the organization to the larger SPI network; management, specifically senior management, for their support for the SPI efforts; the organization's software engineering process group (SEPG), who act as change agents and facilitators for the SPI efforts; technical working groups or teams engaged in focused improvement activities, such as implementing a given key process area of the CMM; and the individual stakeholders or practitioners within the organization, who are really the targets of the overall SPI effort.

Interactions between these networks occurred not just through the liaisons, but also through other mechanisms. These included interventions within the organization or with its management team by a gatekeeper or a key external consultant. Consultants bring the experience of having seen and 
having tried things before which the adopter organization often lacks; while the SPIN can share experiences that they have had across organizations.

This illustrates the key role that social networks play in the diffusion and adoption of these SPI approaches. Next, we address key aspects of how inter-organizational and interpersonal networks operate in such an environment.

\subsection{Network Mechanisms}

We were able to identify a number of mechanisms in networks, which support and/or hinder the diffusion of SPI approaches.

- Importance of network: Network connections between adopting organizations and the larger external network are extremely important in supporting adoption decisions by demonstrating evidence of visible success, bringing in scarce expertise into the organization to support unfreezing or change activities or building commitment/sponsorship, building skills and mentoring, and sharing lessons across organizations.

- Proxies: While certain research centers, such as the SEI, are essential to developing innovations, it may be that certain key individuals may act as a proxy for the organizational innovation source. In the case of the Scandinavian SPI network, while much information was available from the SEI through classes in the USA or from its website, the proxy for the SEI in the network was a single, well-respected researcher/consultant who worked extensively with Scandinavian companies and universities.

- Key movers: The role of influence is seen in these networks. Certain organizations, because of their role as stars or because of their perceived position within industry, are seen as being key movers or reference cases to emulate.

- Collaborative groups: These groups, such as a SPIN, provide a collaborative forum for individuals to share different perspectives, understand their different focus and drivers for change, and share experiences in a manner mostly free of competitive pressures. Involvement in these groups reinforces adoption and diffusion decisions, and supports persistence in managing change.

- Multiple, interlocking networks: The liaisons in adopting organizations were linking pins between multiple, interlocking networks. One network was the larger regional or global SPI network, while another was the local process improvement-focused network within their organization. 
- Emergent properties of networks: These networks adapted over time, as individuals changed positions, as research postures matured, as SPINs and conferences grew.

\section{ISSUES AND CHALLENGES}

Successful software process improvement activities rely on a network of networks. These multiple, interlocking networks serve to make this a very small world and support adoption and diffusion of SPI innovations through a wide variety of roles that are involved in these networks. These include nodes internal to the adopting organization, such as individual practitioners, improvement teams or technical working groups; software engineering process groups, organizations and their management; as well as external nodes, such as consultants, university researchers, and SPIN groups and conferences.

In these networks, there is an apparent tension between purposeful activities and accidents and serendipity. Personal connections and influence are extremely important in effective linkages. Tensions also exist between collaborative and competitive behaviours, especially in the larger, intraorganizational SPI networks or the SPIN groups.

Differences in developing effective adoption and diffusion activities also appear in examining the kinds of entities that are prevalent in intraorganizational and inter-organizational SPI networks. In intra-organizational networks, the star nodes, such as SPIN groups, are often seen as communities of practice, operating as a self-organizing group. Within an organization, the SEPG is often a task force team tasked to perform certain activities. The strength of ties (close vs. loose), level of formality (informal vs. highly structured), and organizational structures (traditional, hierarchical structure vs. a looser volunteer committee) are all characteristics that can differentiate internal star groups, such as an SEPG, and external star groups, such as a SPIN group. Thus, while both are network structures, the approaches for supporting adoption and diffusion of software process improvement may differ between intra- and inter-organizational networks.

\section{REFERENCES}

Curtis, B. (2000). The global pursuit of process maturity. IEEE Software, Vol. 17, No. 4, pp. 76-78.

Dale, B. G. et al. (1994). Total Quality Management - An Overview (2nd edition). In Dale, B. G. (ed.), Managing Quality. Prentice Hall, New York, USA 
Fowler, P., L. Levine. (1993). A Conceptual Framework for Software Technology Transition (Tech. Rpt. CMU/SEI-93-TR-31). Software Engineering Institute, Carnegie Mellon University, Pittsburgh, PA, USA.

Humphrey, W. \& Sweet, W. (1987). A Method for Assessing the Software Engineering Capability of Contractors (Tech. Rpt. CMU/SEI-87-TR-23). Software Engineering Institute, Carnegie Mellon University, Pittsburgh, PA, USA.

Humphrey, W. S. (1989). Managing the Software Process. Addison-Wesley, Reading, MA, USA

Johansen, J., L. Mathiassen (1998). "Lessons learned in a National SPI Effort." EuroSPI '98, Gothenburg, Sweden, November 16-18, 5.1-17

Kautz, K. (2000). Editorial for a Special Issue on Diffusion and Adoption of Information Technology, Information, Technology and People, Vol. 13, No. 1, pp. 5-10

Kautz, K. (2001). Editorial for a Special Issue on Trends in Software Process Improvement in Scandinavia, in Scandinavian Journal of Information Systems, Vol. 13, pp. 3-6

Kautz, K., E. A Larsen (2000). Diffusion Theory and Practice: Disseminating quality management and software process improvement innovations (revised version), Information, Technology and People, Vol. 13, No. 1, pp. 11-26

Kautz, K., P. A Nielsen (2000). Introducing Software Process Improvement: Two Cases of Technology Transfer, In Proceedings of the Hawaii International Conference on System Sciences (HICSS-33) 2000, Maui, USA, January 4-7,2000.

Mobrin, J. \& Wästerlid, A. (1997). The Improvement Engine of the Ericsson System Software Initiative, In Proceedings of the European SEPG 1997 Conference. ESPI Foundation, Milton Keynes, UK.

Paulk, M.C., Weber, C., Curtis, B., \& Chrissis, M.B. (1995). The Capability Maturity Model: Guidelines for Improving the Software Process. Addison-Wesley, Reading, MA, USA.

Robertson, M. et al. (1996). Interorganizational networks and the diffusion process: the case of networks not working. In Kautz, K. \& J. Pries-Heje (1996) (eds.), Diffusion and Adoption of Information Technology, Chapman \& Hall, London, UK, pp. 147-159.

Software Engineering Institute. (2003a). Process Maturity Profile - Software CMM ${ }^{\circledR}$ CBA IPI and SPA Appraisal Results, 2003 Mid-Year Update. Software Engineering Institute, Carnegie Mellon University, Pittsburgh, PA, USA.

Software Engineering Institute. (2003b). Software Process Improvement Network (SPINs). Software Engineering Institute, Carnegie Mellon University, Pittsburgh, PA, USA. (http://www.sei.cmu.edu/collaborating/spins/). 